\title{
DROGAS E ÁLCOOL NA UNIVERSIDADE: PROIBIÇÕES, SILENCIAMENTOS E DIÁLOGOS
}

\author{
DROGAS Y ALCOHOL EN LA UNIVERSIDAD: PROHIBICIONES, \\ SILENCIAMENTOS Y DIÁLOGOS
}

\author{
DRUGS AND ALCOHOL IN THE UNIVERSITY: BANS, SILENCES AND \\ DIALOGUES
}

Karla Helene Marques LIMA ${ }^{1}$

Cristiane Gonçalves da SILVA ${ }^{2}$

Rosilda MENDES ${ }^{3}$

RESUMO: O objetivo deste artigo é analisar os significados estudantis e institucionais atribuídos ao uso de álcool e outras drogas na Universidade Federal de São Paulo (UNIFESP), campus Baixada Santista. A metodologia utilizada foi qualitativa com produção dos dados por meio de entrevistas semiestruturadas realizadas com estudantes e levantamento documental sobre a política de álcool e outras drogas da Universidade. Os dados foram analisados por meio de análise do conteúdo. O resultado demonstra que mesmo com a iniciativa de diálogo fomentada pela Universidade, existem lacunas na discussão sobre o consumo de álcool e outras drogas, apontando para a necessidade de incorporar essa temática nos espaços de formação, cumprindo assim, mais integralmente o papel pedagógico da Universidade.

PALAVRAS CHAVE: Álcool e drogas. Universidade. Autonomia. Redução de danos.

RESUMEN: El proposito de este estudo es comprender las razones estudantiles y instinucionales atribuidos al uso/consumo de alcohol y otras drogas/estupefacientes en la Universidad Federal de São Paulo (UNIFESP), campus Baixada Santista. Basándose en la investigación cualitativa con produccíon de datos mediante entrevistas semiestructuradas realizadas con estudiantes y levantamiento documental sobre la política de alcohol y otras drogas de la universidad. Los datos fueron analizados mediante análisis de contenudo. El resultado demuestra que incluso con iniciativa del diálogo por la Universidad, existen deficiências em la discusión sobe el consumo de alcohol y otras drogas, apuntando sobre la necesidad de incorporar este temática em los ámbitos de educación, cumpliendo así, más plenamente el papel pedagógico de la Universidad.

\footnotetext{
${ }^{1}$ Universidade Federal de São Paulo (UNIFESP), Santos - SP - Brasil. Mestre profissional Ensino em Ciências da Saúde. E-mail: karla.helene@unifesp.br

2 Universidade Federal de São Paulo (UNIFESP), Santos - SP - Brasil. Docente Adjunta do Departamento de Políticas Públicas e Saúde Coletiva, Instituto de Saúde e Sociedade. E-mail: cristiane.goncalves.silva@gmail.com

3 Universidade Federal de São Paulo (UNIFESP), Santos - SP - Brasil. Docente Associada do Departamento de Políticas Públicas e Saúde Coletiva, Instituto de Saúde e Sociedade. E-mail: rosilda.mendes3@gmail.com
} 
PALABRAS CLAVE: Alcohol y drogas. Universidad. Autonomía. Reducción de daños.

ABSTRACT: The objective of this article is to analyze the student and institutional meanings attributed to the use of alcohol and other drugs at the Federal University of São Paulo (UNIFESP), Baixada Santista. The qualitative methodology was used with data production via semi structured interviews with students and a documentary survey on the policy on alcohol and other drugs at that university. The data were analyzed through content analysis. The result shows that even with the university-led dialogue initiative, there are gaps in the discussion about the consumption of alcohol and other drugs, pointing to the need to incorporate the issue into the formative areas of the university, and therefore fulfilling its pedagogical role thoroughly.

KEYWORDS: Alcohol and drugs. University. Autonomy. Harm reduction.

\section{Introdução}

Este artigo tem por base a pesquisa desenvolvida durante mestrado profissional que objetivou analisar os significados estudantis e institucionais atribuídos ao uso de álcool e outras drogas em uma Universidade Federal. $\mathrm{O}$ interesse pelo tema nasce da observação do consumo importante de álcool e outras drogas por estudantes da Unifesp campus Baixada Santista, na condição de enfermeira ${ }^{4}$ em um núcleo de assistência estudantil, denominado Núcleo de Apoio ao Estudante (NAE), instituído em todos os campi da Universidade Federal de São Paulo (UNIFESP), aliada ao fato de não haver, naquele momento, uma política institucional voltada para as questões de álcool e drogas. Tal constatação foi observada durante os atendimentos aos discentes.

Compreender o fenômeno das drogas, tanto nas Universidades quanto na sociedade em geral, implica em se deparar com uma complexidade que revela diferentes formas de dialogar e explicar o uso de álcool e de outras drogas. Embora possam ter significados/sentidos em contextos sociais estritos, esses não cobrem a totalidade de sentidos atribuídos às vivências relacionadas às drogas, dada sua diversidade de ancoragens: pessoais, sociológicas, antropológicas, psicológicas e econômicas (TIBURI; DIAS, 2013). A perspectiva de uma política de guerra às drogas é uma estratégia com pouco sucesso, como demonstram inúmeros estudos que apontam que o modelo proibicionista não diminui o uso de álcool e de outras drogas, especialmente entre adolescentes e jovens (COUTINHO; ARAÚJO; GONTIÈS, 2004; CARLINI et al,

4 A autora principal é enfermeira do campus e as outras autoras foram orientadoras do trabalho desenvolvido por ela durante o mestrado. 
2006; FORTE， 2007; ANDRADE; DUARTE; OLIVEIRA， 2010; ADADE; MONTEIRO, 2013; UNODC, 2013).

Importante destacar que, de acordo com muitos pesquisadores, há outros elementos que ampliam a discussão sobre a temática. Bucher (2007, p. 117) afirma, por exemplo, que “[...] não existem sociedades sem drogas e sim uso de diferentes substâncias utilizadas devido à capacidade ou incapacidade da sociedade em lidar com tensões e disfuncionamentos [...]”. Ainda segundo este autor, “[...] as drogas, quando muito, revestem a carapuça de bode expiatório do moderno 'mal-estar na cultura', ao lado de outros fenômenos de marginalização social, como a delinquência, o alcoolismo, os suicídios, a violência urbana [...]” (BUCHER, 2007, p 117).

Para Tiburi e Dias (2013), a compreensão da questão ambígua entre dor e prazer ocasionada pelas drogas está necessariamente condicionada à superação do moralismo. Para vencê-lo e, com isso, superar a atual lógica de culpabilização do sujeito, será necessário superar os reducionismos e os discursos simplórios antidrogas. Para tanto, Campos (2005, p. 214) tem proposto "construir uma educação sobre drogas a partir do entendimento ampliado, uma 'drogalidade' que também inclua a subjetividade, as fantasias, os valores, a busca do prazer, as normas, as representações pessoais e sociais", fundamento extremamente importante ao lidar com a juventude, principalmente universitária.

Estudos apontam também o envolvimento expressivo de uso prejudicial de álcool e de outras drogas pela juventude (COUTINHO; ARAÚJO; GONTIÈS, 2004; CARLINI et al, 2006; ANDRADE; DUARTE; OLIVEIRA, 2010). Contudo, Hobsbawm (1995) destaca que, ligações com o universo cultural, político, econômico, social, afetivo ao qual o jovem se insere são essenciais e se constituem como primordiais para a análise desta etapa da vida. O autor nos lembra que a categoria 'juventude' não existe por si só, não se consolida enquanto uma categoria universal que pode ser apreendida em qualquer tempo e em qualquer espaço, ou seja, quando falamos em juventude é sempre importante ter em conta a sua pluralidade constitutiva e, ao mesmo tempo, contextualizar a singularidade do sujeito com quem estamos falando.

No Brasil, o Estatuto da Criança e do Adolescente (ECA) diz que o adolescente é aquele que tem até 17 anos, 11 meses e 29 dias e poderíamos imaginar que a juventude seria o tempo posterior à adolescência. Todavia, essas fronteiras além de serem difíceis de demarcar não podem ser consideradas de forma rígida. Ser jovem não depende somente da idade como característica biológica, como condição do corpo e 
tampouco depende da condição social. É preciso ter em conta que há uma circunstância cultural que emana de ser socializado com códigos diferentes, relacionado à forma como jovens incorporam modos de perceber e de apreciar o mundo (MARGULIS; URRESTI, 1996).

As discussões em torno da questão do uso de álcool e de outras drogas, dada sua multidimensionalidade, pode tornar-se um campo minado. Dependendo do recorte que se faça, corre-se o risco de perder a noção de unidade, especialmente quando tentamos discutir uma relação entre juventude e drogas. Se culturalmente o uso de álcool e de outras drogas têm sentidos variados para os sujeitos que utilizam, há que se considerar igualmente as estratégias ou significados que são socialmente construídos sobre este uso.

É preciso ter em conta que as construções e representações em torno do uso de álcool e de outras drogas estão diretamente relacionadas com o contexto em que nos inserimos. Nossa forma de inserção no mundo é necessariamente social, e sem a mediação de outro ser-humano para a apropriação da cultura não temos acesso às formas de socialização que nos inserem na categoria de humanos. Essa distinção implica a compreensão de que os conteúdos dos quais nos apropriamos para configurar os significados sobre nós e o mundo somente acontecem no interior de relações. São as relações que compõem o cenário no qual as disputas pela afirmação de significados são mediadas igualmente pelos sentidos pessoais que aquela experiência traduz.

Em nossa cultura, existe uma trajetória prototípica que é baseada num continuum de referências que vão dando sustentação à vida e que, no geral, não se contrapõem, mas, pelo contrário, são complementares e vão se revezando no tempo e no espaço (BERGER; LUCKMANN, 2013). Estamos falando dos processos de socialização primária e secundária que na nossa cultura correspondem à família e posteriormente aos grupos sociais extensos como amigos, colegas, relações de trabalho, lazer, cultura, vizinhança etc.

Para Sarti (2004), o jovem não tem um lugar social definido e, em virtude disso, ocupa socialmente o que seria uma "projeção do mundo adulto", dada pelas expectativas familiares. No tocante ao uso de drogas, a autora diz que existe uma tendência de encontrar no jovem o "indesejável na família". Para ela, as projeções dos problemas familiares sobre os jovens levam à idealização do mundo familiar, ao mesmo tempo em que torna difícil pensar o conflito como algo inerente às relações nessa esfera. 
Piaget (1974) e Vygotsky (1984), autores que estudam o desenvolvimento, apontam que os processos de socialização não são entidades estanques. Existe um constante diálogo que se expressa por assimilações, contradições, conflitos e aceitações. O que não podemos deixar de observar é que as instituições compõem esse rol, e, dessa forma, não podem agir como se estas questões não lhe dissessem respeito, devolvendo o "caso" à família, à política ou à saúde em sua dimensão reparadora. A entrada dos jovens na Universidade traduz fortemente a questão de socialização. Vindos de diversas origens familiares, classes sociais, cor/raça, gêneros, posicionamentos políticos, orientações sexuais, religiosidade em distintos contextos históricos, estes estudantes em sua grande maioria jovens - configuram uma condição peculiar: o choque entre a tradição na qual foram educados e as possibilidades de releitura do mundo que o acesso acadêmico oferece.

A socialização que a Universidade suporta, enquanto instituição, é diversa, rica de encontros e desencontros. Os dramas, pessoais e coletivos, que derivam dessa socialização podem ser significativos para entender a questão do uso de álcool e de outras drogas. Como observamos no cotidiano, o uso de drogas tem significados potentes no que concerne às novas experiências preceptorais, ao entrosamento, à constituição de relações, à fuga da pressão relacionada à máquina institucional.

\section{A questão das drogas na Universidade}

Durante muitos anos, a UNIFESP constituiu-se hegemonicamente com graduações e pós-graduações na área da saúde, sendo reconhecida nacional e internacionalmente pelo seu curso de Medicina no campus de São Paulo. A partir de 2006, inicia seu processo de ampliação e, após 2007, propulsionada pelo Plano de Reestruturação e Expansão das Universidades Federais Brasileiras (REUNI), e adere à lógica da expansão do Governo Federal. Inicia aí seu processo de crescimento, primeiramente com a criação de um campus na Baixada Santista e, posteriormente, com a criação de outros campi: Diadema, Guarulhos, Osasco e São José dos Campos. Com o processo de expansão territorial houve a ampliação das áreas de conhecimento, com graduações também nas áreas de humanas e exatas, tornando-se uma Universidade multicampi e multitemática (UNIFESP, 2011).

Tais transformações levaram à necessidade de mudança na estruturação do estatuto da Universidade para abarcar as diferenças e na formulação de uma política 
específica para apoiar a permanência estudantil. Há de se considerar que o intuito da expansão aumentaria o número total de vagas e as especificidades de estudantes de condições socioeconômicas, culturais e de vida significativamente distintas. Diante da necessidade dessa reorganização, em março de 2010 o novo estatuto foi aprovado pelo Conselho Universitário (CONSU), que estabeleceu a criação do Conselho de Assuntos Estudantis (CAE), precursor da Pró-Reitoria de Assuntos Estudantis (PRAE).

O estatuto também definiu as várias competências deste Conselho, como "promover políticas e programas de apoio à permanência do aluno, tais como moradia, transporte, alimentação e saúde" (UNIFESP, 2011a, p. 16). Assim, em $1^{\circ}$ de outubro de 2010 a PRAE foi instituída com a missão de "[...] desenvolver ações institucionais direcionadas para o acesso e permanência de estudantes de graduação, residência e pósgraduação da UNIFESP, visando a excelência na formação integral, pautada nas responsabilidades ética, social e ambiental [...]" (UNIFESP, 2013, p. 5).

A PRAE foi subdividida em quatro coordenadorias, com objetivos específicos em consonância com o Plano Nacional de Assistência Estudantil (PNAES). Esse Plano foi criado pelo decreto presidencial n. ${ }^{\circ}$ 7.234, de 19 de julho de 2010, com o intuito de contribuir com as condições necessárias para permanência estudantil nas Instituições Federais de Ensino Superior (IFES). O PNAES deu sustentação ao binômio acesso e permanência do estudante universitário ao articular estratégias que compreendiam mudanças políticas, ampliação estrutural e concessão de auxílios visando à democratização do ensino superior no país (BRASIL, 2010).

Para que a política de permanência estudantil fosse executada, foi implantado em cada campus da UNIFESP um núcleo denominado Núcleo de Apoio ao Estudante (NAE), composto por servidores técnicos administrativos da área de saúde, assistência social e pedagogia, além de um coordenador. Esse Núcleo é responsável por acolher os estudantes nas Universidades de forma integrada, considerando distintas demandas: saúde, sociais, psicológicas, pedagógicas, realizando a intersecção entre a Pró-Reitoria de Assuntos Estudantis e suas coordenadorias, a fim de efetivar ações nos campi.

No campus Baixada Santista, o NAE passa a ser solicitado a atuar em várias demandas e, entre elas, a atenção ao uso prejudicial de álcool e de outras drogas. Essa situação suscita o questionamento acerca dos mecanismos de intervenção que necessitariam ser incorporados no cotidiano dos estudantes para reduzir os danos. Nesse contexto, portanto, é que se instaura efetivamente a necessidade de uma política institucional sobre álcool e de outras drogas. Embora a UNIFESP seja considerada uma 
referência no campo dos estudos sobre esta temática, na época da realização do estudo, ainda não possuía uma política institucional voltada à comunidade acadêmica.

Cabe destacar que até 2011, o consumo de álcool era permitido dentro do espaço físico da UNIFESP, principalmente no campus São Paulo, onde a venda de bebidas alcoólicas era a principal fonte de renda da Atlética, coletivo de estudantes que realiza atividades esportivas e festas universitárias. Entretanto, a partir do final de 2011, por decisão do CONSU, foi aprovada uma medida que proibiu a venda e o consumo de álcool dentro da instituição, ocasionando uma reação de descontentamento por parte de alguns estudantes, que tiveram que transferir suas festas para outros lugares.

Diante das diversas questões em torno do uso de álcool e de drogas entre estudantes, em julho de 2013 a UNIFESP dá o primeiro grande passo no processo de reflexão sobre a temática das drogas, com a publicação de uma edição especial do "Jornal Entrementes" de circulação interna, organizado pela Reitoria da UNIFESP. A edição foi voltada à reflexão sobre as drogas a partir de dimensões que costumam gerar polêmicas e divergências de posicionamento, como: internação compulsória, política de Redução de Danos, legalização, comércio e consumo de drogas. Conceituados pesquisadores da Universidade, cada qual com suas concepções e posicionamentos, apresentaram discussões sobre os temas, de formas distintas. A edição contou também com texto de gestores da UNIFESP, como a Pró-Reitora de Assuntos Estudantis. Essa iniciativa foi de grande relevância, considerada nesta reflexão como o marco da discussão ampliada relacionada à temática do uso de álcool e de outras drogas, e também o marco de um momento importante na história da Universidade.

Outro movimento de reflexão, fomentado por esta Pró-Reitoria, foi uma matéria publicada em 2013 em seu jornal denominado "Plural e Democrático", também de circulação interna na UNIFESP. O título da capa provocava a reflexão: "DROGAS NA UNIVERSIDADE - Vamos conversar?” e a matéria apresentava o desafio de construir uma política sobre drogas, além de lançar a proposta de constituição de fóruns coletivos específicos sobre as drogas em todos os campi da UNIFESP, na tentativa de uma construção conjunta com toda a comunidade acadêmica, trazendo para a discussão posicionamentos de pesquisadores internos e externos à UNIFESP, pessoas ligadas aos coletivos de usuários de drogas e de luta pelos direitos humanos, além de estudantes, técnicos e docentes.

Nessa trajetória de reflexão sobre álcool e outras drogas realizadas pela UNIFESP, em março de 2014, foi realizado um evento inaugural organizado pela Pró- 
Reitoria de Assuntos Estudantis com objetivo de iniciar o processo para elaboração de uma política sobre essas questões na UNIFESP, definindo etapas e aprofundando discussões em torno da temática de álcool e drogas. Como parte do processo, pactuado nesse evento, foram organizadas rodas de conversa e outras atividades e eventos relacionados a essa temática em todos os campi.

\section{Metodologia}

Foi realizada uma pesquisa qualitativa que pretendeu captar os significados/sentidos atribuídos ao uso de álcool e de outras drogas pelos estudantes universitários que estavam no último ano de graduação na UNIFESP Baixada Santista, tanto do Instituto Saúde e Sociedade como do Bacharelado Interdisciplinar em Ciências do Mar. A escolha por estudantes na etapa final da graduação justificou-se por terem percorrido a trajetória universitária e, portanto, maiores chances de possuírem repertório ampliado para abordar essa temática. A produção de dados foi realizada em duas etapas: a) levantamento e análise documental sobre álcool e outras drogas, relatório de gestão, jornais, sites, artigos e demais materiais impressos da Universidade; b) realização de entrevistas semiestruturadas.

A análise documental foi realizada a partir de documentos produzidos pela Universidade, datados a partir da constituição da Pró-Reitoria de Assuntos Estudantis em outubro de 2010 até o término em dezembro de 2014, que fazem referência à questão das drogas, entendendo que estes documentos traduzem as políticas da Universidade sobre o tema.

As entrevistas semiestruturadas foram mediadas por estímulos interativos, que consistiram na apresentação de trechos de falas de estudantes da Universidade de modo a manter a dinâmica de um diálogo. O processo de seleção inicial dos estudantes foi aleatório, assim, abordamos um estudante e explicitamos a pesquisa e nossos objetivos. A partir desse estudante foi aplicada a técnica de bola de neve na qual um estudante indicou mais dois para participar da pesquisa (MINAYO, 2010).

Ao todo foram entrevistados dez jovens, sendo sete deles do Instituto Saúde e Sociedade (um de educação física, um de nutrição, três de psicologia, um de serviço social e um de terapia ocupacional) e os outros três estudantes do curso Bacharelado Interdisciplinar em Ciência e Tecnologia do Mar. Dos dez estudantes entrevistados, seis cursavam a Graduação em período integral, dois no período vespertino e dois no 
período noturno. $\mathrm{Na}$ análise dos dados, esses estudantes foram identificados de E01 a E10. As entrevistas foram gravadas e transcritas de modo a garantir confidencialidade das informações. Todos os estudantes assinaram o Termo de Consentimento Livre e Esclarecido (TCLE). O estudo foi aprovado pelo Comitê de Ética e Pesquisa (CEP), sob o número 777.136.

Para organização das informações foi realizada leitura e releitura sistemática das transcrições das entrevistas que auxiliaram na construção das categorias de análise. Nesse processo de construção, foi elaborada uma tabela para organização dos dados, que ajudou a evidenciar as questões mais significativas que emergiam nas falas dos sujeitos e nos documentos.

Os dados produzidos em campo foram organizados através de categorização e análise utilizando o que Minayo (2010) chama de triangulação dos dados, que consiste na recategorização dos elementos levantados por métodos de coleta diferentes, buscando produzir novas categorias de análise. A triangulação dos dados se caracteriza pelo cruzamento e combinação de múltiplas técnicas que podem ser vistos como grades que ajudam a observar e compreender a realidade (MINAYO, 2010). Três categorias foram identificadas, mas, para fins deste artigo, iremos abordar a categoria Drogas na Universidade: proibições, silenciamentos e diálogos.

\section{Drogas na Universidade: proibições, silenciamentos e diálogos}

Na UNIFESP, durante muito tempo, houve um silenciamento em relação à política interna sobre álcool e outras drogas. Todavia, como destacado anteriormente, a criação da Pró-Reitoria de Assuntos Estudantis foi abrindo espaços de diálogo. Contudo, diálogo e silenciamento não são movimentos estáticos e isolados, como se ao terminar um começasse o outro; ao contrário, existe um potente diálogo no silenciamento e um silenciamento no diálogo, como se fossem processos coconstituintes. Tal constatação aponta a necessidade de um olhar mais detalhado para compreendermos tais movimentos.

Começaremos a falar a partir do silêncio porque este aponta para uma contradição nesse campo. Silêncio? Sobre drogas existe uma série de discursos públicos e privados que colocam esse tema em voga. Esta aparente discussão sobre drogas produz inúmeras indagações para as quais não há respostas definitivas. Assim, são nessas lacunas, silenciamento, espaços e hiatos que fluem discursos - políticos, 
morais, legais e de políticas públicas de saúde - que os sujeitos agenciam, e que são também os discursos que os constituem. Praticamente todos os entrevistados do campus Baixada Santista fizeram menção ao silêncio relacionado à questão das drogas, como pode ser observado a seguir:

\footnotetext{
"Não temos nenhuma aula que trate destas questões" (E08).

"Eu lembro da palavra maconha ter sido dita somente no primeiro ano por um professor de IS , foi só desta vez”(E06).
}

"[...] a gente trabalhou a questão prisional, fala um pouco aí de drogas, mas não nesse sentido, e nada relacionado à Universidade” (E04).

“[...] mas nunca houve ou não me lembro de nenhuma roda de conversa com essa temática ou algo que fosse no sentido educativo para os próprios estudantes" (E10).

Esses discursos apontam existir uma potente questão a ser encarada pela Universidade, diante de um tema tão complexo que pode trazer em seu bojo estigmas, preconceitos e moralismos que têm consequências para a vida acadêmica. Os estudantes entrevistados, inclusive, enfatizaram a importância da discussão e reflexão como forma de (re)pensar o padrão normativo socialmente aceito.

As entrevistas também apontaram a importância do papel da Universidade no processo de construção de um novo olhar ou de novos parâmetros sobre uso de álcool e de outras drogas na sociedade, especialmente para a própria comunidade universitária. O desejo por realizar diálogos com a Universidade pareceu importante também por indicar uma espécie de "recusa" aos modelos prontos de inteligibilidade sobre a questão das drogas. Os estudantes, a partir de seus contextos, pareceram interessados em construir parâmetros de sociabilidade mais condizentes com suas vivências concretas, levando também em consideração o outro. Assim, as afirmativas dos estudantes sobre ausência de diálogo sobre drogas também são instigantes considerando que o Instituto de Saúde e Sociedade do campus Baixada Santista tem todos os cursos com atuação importante na área da saúde.

A temática das drogas está posta socialmente, sobretudo do ponto de vista moral, político e legal - como uma questão negativa a priori (HART, 2014). Essa questão não pode ser ignorada porque incide sobre comportamentos e percepções. O silenciamento

${ }^{5}$ IS é o acrônimo usado por estudantes, docentes e técnicos do Instituto Saúde e Sociedade para referir o Eixo Comum "O Ser Humano e sua Inserção Social” que trabalha conteúdos das ciências sociais e humanas, constitutivo da matriz curricular dos seis cursos do Instituto. 
passa a fazer parte do jogo de prescriçõos que ajudam a manter a temática longe de problematizações que possam movimentá-la e promover reflexões. Esta questão aparece na fala de um estudante:

A gente nunca trabalhou esse tema especificamente, não que eu me lembre! Sei que tem palestra... A semana canábica. Mas, na formação, nunca vi. Não me lembro de nada... A gente trabalhou a questão prisional. Fala um pouco aí de drogas. Mas não nesse sentido... E nada relacionado à Universidade. Só questão extra, de tráfico, de direitos humanos, de ver a pessoa sob outro olhar, mas falando do traficante, não das drogas. De como trabalhar essa questão, somente um olhar mais humano sobre aquela população. E ainda assim, muito pouco. Muito vagamente (E04).

Nesta fala, é possível perceber silenciamento e, quem sabe, a não apropriação de conteúdos programáticos sobre drogas que aconteceram no campus Baixada Santista. Tiburi e Dias (2013), no livro Sociedade Fissurada, fazem uma importante reflexão sobre o moralismo que abarca a questão das drogas, que nada mais é que uma moral petrificada e que, portanto, "Pensar eticamente a questão das drogas é tarefa urgente no contexto de moralismo ditatorial que tem validade como falsa consciência, a ideia de uma verdade aceita por todos e que vige apenas porque repetidas vezes sustenta as coisas como elas são" (TIBURI; DIAS, 2013 p. 127). Nessa perspectiva, um dos entrevistados apresenta, diversas vezes, colocações acerca da Universidade como uma instituição que prefere ignorar um problema a ter que lidar com questões que envolvam aspectos legais, que possam levar a impasses jurídicos:

São poucos debates, por ser um espaço universitário, naturalmente há
mais debates, mas não existe nenhuma aula que aborde
especificadamente a questão das drogas, as únicas discussões em sala
são relacionadas às desigualdades sociais acarretadas pelas drogas.
A guerra as drogas é uma expressão discutida, naturalmente estas
questões relacionadas às drogas vão aparecer no decorrer do curso,
entretanto não há nenhum espaço destinado a estas questões no
curso. Nenhum espaço onde se faça este debate. O meu acumulo é
muito mais extra Universidade do que no espaço da Universidade. O
espaço que seja institucionalizado não existe (E05).

É notória a importância da existência de espaços de reflexão internos, em que os diferentes usos de álcool e de outras drogas pelos universitários sejam refletidos através de uma postura acolhedora. Não adianta mediar somente o uso do outro ou não 
considerar a pluralidade de usos e contextos. É preciso implicar-se para entender como os jovens universitários lidam com a questão do uso de álcool e de outras drogas.

Algumas pesquisas discutem a necessidade em incorporar a educação sobre drogas na matriz curricular dos universitários (Kerr-Corrêa et al (1999) e Portugal et al (2008). O estudo de Wagner e Andrade (2008) aponta, como conclusão, a necessidade de serem realizados mais estudos acerca da relação entre universitários e uso de drogas. Araújo, Gontiès e Nunes Júnior (2007) discutem, ao pesquisar as representações sociais sobre a cocaína entre universitários, a necessidade permanente de inclusão de disciplinas que possibilitem debates entre os pares. Silva et al (2006) também indicam a necessidade da criação de disciplinas nas Universidades para a discussão sobre drogas e sobre a redução da carga de estresse sobre os estudantes.

Contudo, a discussão interna nas Universidades sobre o uso de álcool e de outras drogas geralmente são silenciadas nas instituições até que alguma tragédia ocorra. Nesse momento rapidamente iniciam-se as discussões rasas sobre o caráter 'autodestrutivo' dos jovens e das drogas (SERRANO, 2015). É comum que, ao abordar a questão do uso de drogas, as Universidades apresentem uma preocupação muito mais legal do que moral e ética, o que leva a medidas restritivas, como a proibição de festas e principalmente do consumo de álcool dentro da área física da Universidade, isentandose institucionalmente de possíveis problemas jurídicos que decorram do uso nas suas dependências.

Ainda que o interesse da UNIFESP em levar adiante a discussão tenha sido iniciado em 2013, rumo à construção de uma política interna sobre álcool e outras drogas, isto não apareceu nas narrativas dos estudantes entrevistados. É possível considerar que, naquele momento, se tratava de um movimento incipiente e, além disso, é preciso ter em conta que o processo de construção ocorre em cenários de disputas acerca do modo de se compreender o uso de drogas e sobre o modelo de atenção dada ao uso, em termos de políticas, dentro da própria Universidade. No momento de um processo recém-iniciado, não era possível identificar uma posição institucional. Entre os estudantes entrevistados não houve referência sobre este processo de discussões iniciado pela Reitoria. Apenas um estudante fez referência, quando questionado, ao jornal interno da UNIFESP, edição especial sobre drogas. “Eu vi este jornal!” (E10).

Nos últimos anos a UNIFESP vem avançando no processo rumo à elaboração de políticas institucionais sobre álcool e outras drogas. Entretanto, é preciso que a discussão sobre a temática seja cada vez mais ampliada e incorporada no próprio tripé 
que define a Universidade: ensino, pesquisa e extensão de todas as carreiras. É preciso considerar as posições antagônicas sobre drogas que estão, inclusive, presentes na UNIFESP e que aparecem no processo que pretende definir uma política interna.

Ainda que em um cenário de posicionamento que indica polarizações sobre o uso de drogas, cabe à Universidade discussões qualificadas e criação de mecanismos de proteção à saúde dos estudantes, quando demandada. É preciso também refletir que uma política centrada no proibicionismo não tem possibilidade de alcançar resultados positivos, dado que ao proibir e penalizar o uso de drogas desencadeia-se outras estratégias de consumo, que em certas condições podem ser mais danosas.

Os estudantes entrevistados referiram à falta de uma política sobre uso de álcool e de outras drogas na UNIFESP, além da falta de informações e ações de educação promovidas pela Universidade. Salientaram também que esta seria uma questão complicada e que, a princípio, a Universidade não precisaria ser a favor ou contra, mas deveria refletir sobre tais questões. Na fala apresentada a seguir, o estudante não espera que ocorra a liberação do uso de álcool e de outras drogas a priori, mas espera prioritariamente que exista acolhimento, orientação e compreensão:

Eu não tenho muita clareza da política da UNIFESP, por exemplo, em relação ao uso de drogas. Sei que é proibido, mas não tenho muita clareza da política. Mas assim, eu acho que é um debate difícil, a princípio eu acho que não precisaria ser permitido o uso de drogas tanto lícitas como ilícitas dentro da Universidade... A princípio, não precisa permitir ou apoiar o uso de drogas, mas eu acho que, por exemplo: Como lidar se um estudante vem alcoolizado para assistir aula ou sobre o efeito de alguma outra substância? Acho que precisaria ter uma postura de acolhimento de entender o motivo deste uso, se está sendo um uso abusivo. É importante fazer isso que a gente está conversando, rodas de conversa ou sei lá se rodas de conversa é o melhor dispositivo ou se é outra coisa, se passar filme sobre o uso de drogas e discutir, enfim fazer um ciclo de debates sobre isto (E10).

A dificuldade em estabelecer uma política em relação ao uso de drogas não é exclusiva da UNIFESP. Outras Universidades também possuem dilemas semelhantes. Zalaf e Fonseca (2007), ao pesquisarem o programa de prevenção e acolhimento em caso de uso problemático de álcool e drogas na Universidade de São Paulo (USP), também referem à preocupação da Universidade sobre essa temática. As inúmeras intervenções acontecem quando há dificuldades, mas não há uma política em relação aos encaminhamentos referentes à prevenção e ao tratamento. 
Além de revelarem a ausência de uma política interna na UNIFESP, outras falas fazem referência ao despreparo institucional para lidar com o assunto:

Soube também de casos de segurança da UNIFESP, de agirem de forma repressora com estudantes que estavam fumando [maconha] fora da UNIFESP. Não dentro, fora dos muros da UNIFESP e os seguranças saíram de dentro da UNIFESP, foram até a calçada e reprimiram até agressivamente (E05).

Na cadeia de procedimentos institucionais, a labilidade da política universitária aparece também na ação dos trabalhadores terceirizados, quando a estudante relata caso em que os seguranças tiveram uma abordagem despreparada para com estudantes que estavam usando maconha em espaços externos, ainda que se leve em consideração a lógica de preparo desta categoria de trabalhadores, inspirada numa tendência militarizadora da segurança no Brasil.

Portanto, há questões importantes a serem consideradas no debate, tanto sobre o silenciamento por parte da Universidade em discutir sobre o uso interno de álcool e de outras drogas, como entender o tom moralista que, algumas vezes, são assumidos em debates e etapas do processo. Além disso, é preciso também ter em conta a iniciativa institucional significativa rumo à discussão sobre drogas na Universidade, ainda que aparentemente lábil, considerando o contexto de disputas em tornos da temática.

\section{Considerações finais}

O silêncio que aparece no debate institucional é resultado da dificuldade em assumir posicionamentos em um campo de disputas em que há repercussões sociais a partir daí. A "resposta" para questões relacionadas ao uso de álcool que a Universidade oferece está sujeita ao escrutínio público, além da própria comunidade universitária. Ainda que com dificuldades, é preciso garantir que o processo de construção de uma política continue sendo, progressivamente, mais aberto e participativo e que promova o diálogo, reconheça a diversidade, ainda que em situações de conflito. Deste modo, salienta-se que, ao pensar a temática sobre o uso de álcool e de outras drogas, a Universidade extrapola uma questão de gestão porque necessita do protagonismo de vários atores: estudantes, docentes, técnicos e terceirizados.

Considera-se também importante que a Universidade procure investir em formações e ações de extensão que invistam nos estudantes como redutores de danos, 
atuando no cotidiano e nas interações de sociabilidade, em que o uso de álcool e de outras drogas seja significativo. Mas é preciso também discutir sobre os usos entre docentes, técnicos e terceirizados da Universidade. A formação continuada em redução de danos pode ser uma estratégia importante para ser utilizada nas relações universitárias cotidianas.

É interessante também realizar parceria com congregações de estudantes responsáveis ou promotoras de festas na Universidade, como é o caso das Atléticas neste estudo. Atividades e ações de orientações simples como, por exemplo, oferecimento de água durante as festas. Também é preciso trabalhar junto às empresas terceirizadas para que trabalhadores que interagem diretamente com estudantes, como é o caso dos vigilantes, tenham orientações pautadas na perspectiva dos direitos humanos para a atuação diante do uso de drogas no espaço físico da Universidade ou no seu entorno.

Esta reflexão é finalizada com a afirmação sobre a importância da Universidade em assumir o processo de condução para definição de uma política sobre álcool e drogas, considerando a pluralidade interna de visões e o acúmulo de produções científicas em torno da temática das drogas e as iniciativas de atenção aos usuários existentes. Nesse sentido, é preciso investir na potência de uma construção participativa que considere a pluralidade e que também possa investir em processos contínuos de monitoramento e avaliação. $\mathrm{O}$ tema das drogas deve permanecer nos debates, nas trocas de saberes entre comunidade acadêmica e sociedade e, particularmente, com os estudantes reconhecendo a pluralidade deles e considerando suas experiências, dúvidas e anseios. Deste modo, o estudo e suas reflexões propositivas retomam a importância dos significados estudantis e institucionais sobre álcool e outras drogas. O debate, quando reconhece distintas experiências - de vida, de produções científicas, de políticas - parece possibilitar encontros potentes em meio aos desencontros e esbarrões que possam ocorrer nessa trajetória.

\section{REFERÊNCIAS}

ADADE, M.; MONTEIRO, S. Educação sobre drogas: uma proposta orientada pela redução de danos. Revista Educação e Pesquisa, São Paulo, p. 1-12, 2013.

ANDRADE, A. G.; DUARTE, P. C. A. V.; OLIVEIRA, L. G. I Levantamento nacional sobre o uso de álcool, tabaco e outras drogas entre universitários das 27 capitais brasileiras. Brasília: SENAD, 2010. 
ARAÚJO, L. F.; GONTIÈS, B.; NUNES JÚNIOR, J. Representações sociais da cocaína: estudo comparativo entre universitários das áreas de saúde e jurídica. Estud. Psicol., Campinas, SP, v. 24, n. 3, p. 315-323, 2007.

BARDIN, L. Análise de Conteúdo. 6 ed. São Paulo: Edições 70, 2011.

BERGER, P. L.; LUCKMANN, T. A construção social da realidade. 35 ed. Petrópolis, Rio de Janeiro: Editora Vozes, 2013.

BRASIL. Ministério da Educação. Decreto 7.234 de 19 de julho de 2010. Dispõe sobre o Programa Nacional de assistência Estudantil - PNAES. Diário Oficial da União, 20 jul. 2010. Disponível em: <http://www.planalto.gov.br/ccivil_03/_Ato20072010/2010/Decreto/D7234.htm>. Acesso em: 7 jul. 2015.

BUCHER, R. Ética da prevenção. Psicologia: Teoria e Pesquisa, Brasília, v. 23, n. especial, p. 117-123, 2007.

CARLINI, E. A. et al. II Levantamento domiciliar sobre o uso de drogas

psicotrópicas no Brasil: estudo envolvendo as 108 maiores cidades do país - 2005. São Paulo: CEBRID - Centro Brasileiro de Informações sobre Drogas Psicotrópicas: UNIFESP - Universidade Federal de São Paulo, 2006.

COUTINHO, M. P. L.; ARAÚJO, L. F.; GONTIÈS, B. Uso da maconha e suas representações sociais: estudo comparativo entre universitários. Psicologia em Estudo, Maringá, Paraná, v. 9, n. 3, p. 469-477, 2004.

FORTE, F. M. P. Racionalidade legitimidade da política de repressão ao tráfico de drogas: uma provocação necessária. Estudos avançados, São Paulo, v. 21, n. 61, 2007.

HOBSBAWM, E. A era dos extremos: o breve século XX. São Paulo: Companhia da Letras, 1995.

KERR-CORRÊA, F. et al. Uso de álcool e drogas por estudantes de medicina da Unesp. Rev. Brasileira de Psiquiatria, São Paulo, v. 21, n. 2, p. 95-100, 1999.

MARGULIS, M.; URRESTI, M. La juventud es más que una palavra. In: MARGULIS, A. M.(Org.). La juventud es más que una palabra. Buenos Aires: Biblos; 1996

MINAYO, M. C. S. O Desafio do conhecimento.12 ed. São Paulo: Editora Hucitec, 2010.

PIAGET, J. Epistemologia genética e pesquisa psicológica. Rio de Janeiro: Freitas Bastos, 1974.

PORTUGAL, F. B. et al. Uso de drogas por estudantes de Farmácia da Universidade Federal do Espírito Santos. J. Bras. Psiquiatr., Rio de Janeiro, v. 7, n. 2, p. 127-132, 2008. 
SARTI, C. A. O jovem na família: o outro necessário. In: NOVAES, R.; VANNUCHI, P. (orgs.). Juventude e sociedade: trabalho, educação, cultura e participação. São Paulo: Fundação Perseu Abramo - Instituto Cidadania, 2004.

SERRANO, P. E. Universidade: paternalismo x liberdade. Carta Capital, 16 mar. 2015. Disponível em: <http://www.cartacapital.com.br/sociedade/Universidadepaternalismo-X-liberdade-2605.html>. Acesso em: 8 jul. 2015.

SILVA, L. et al. Fatores associados ao consumo de álcool e drogas entre estudantes universitários. Rev. saúde pública, São Paulo, v. 40, n. 2, p. 280-288, abr. 2006.

TIBURI, M.; DIAS, A. C. Sociedade Fissurada: para pensar as drogas e a banalidade do vício. Rio de Janeiro: Ed. Civilização Brasileira, 2013.

UNIFESP - UNIVERSIDADE FEDERAL DE SÃO PAULO. Estatuto e Regimento Geral da Unifesp. São Paulo: Unifesp, 2011.

UNIFESP - UNIVERSIDADE FEDERAL DE SÃO PAULO. Relatório de Gestão 2010/2013. Pró-Reitoria de Assuntos Estudantis - PRAE. São Paulo: Unifesp, 2013

\section{UNODC - UNITED NATIONS OFFICE ON DRUGS AND CRIME. Relatório} Mundial Sobre Drogas. Viena, 2013.

VYGOTSKY, L. Teoria e metodologia em psicologia. São Paulo: Martins Fontes. 2004.

WAGNER, G. A.; ANDRADE. G. A. Uso de álcool, tabaco e outras drogas entre estudantes universitários brasileiros. Rev. Psiquiatr. Clín., São Paulo, v. 35, n. esp. 1, p. $48-54,2008$.

ZALAF, M. R. R.; FONSECA, R. M. G. S. Na boca do CRUSP: programa de prevenção e acolhimento em caso de uso problemático de álcool e drogas. Esc. Anna Nery, Rio de Janeiro, v. 11, n. 4, p. 650-654, 2007.

\section{Como referenciar este artigo}

LIMA, Karla Helene Marques.; SILVA, Cristiane Gonçalves da.; MENDES, Rosilda. Drogas e álcool na universidade: proibições, silenciamentos e diálogos. Temas em Educação e Saúde, Araraquara, v.14, n.1, p. 156-172, jan./jun., 2018. E-ISSN: 25263471. DOI: $10.26673 /$ rtes.v14.n1.2018.11302

Submetido em: 05/02/2018

Aprovado em: 05/05/2018 